\title{
P33
}

\section{Fault Core Composition and Thickness- displacement Relationships of Extensional Faults in Fine Grained Carbonates}

\section{E. Bastesen* (Centre for Integrated Petroleum Research) \& A. Braathen (University Centre in Svalbard)}

\section{SUMMARY}

Conventional fault seal methods derive transmissibility properties of faults by calculating the shale gouge ratio along the fault. Fault thickness is a key parameter. However, the method does not consider intrinsic fault complexities, such as lenses, varying fault rocks and diagenetic elements. In this study we present a characterization of fault cores in carbonates, based on an analysis of fault composition with respect to the displacement/thickness relationship (D/T). Using a Fault Facies type description of rocks we have compiled and analysed the dimensions and composition of 100 faults cores from Sinai, Oman and Svalbard. These areas display thick succession of sedimentary carbonates truncated by extensional faults. Common volumetric elements of the cores (core facies) include fault rocks such as breccias, calcareous gouge and shale gouge (smear) and layers of calcite precipitated on the walls of slip-surfaces. The overall increase in thickness relative to displacement, showing a lower increase of fault thickness for large scale faults than for small scale faults, fits a power law distribution with an exponent lower than one. The individual fault core facies display different $\mathrm{D} / \mathrm{T}$ than the overall $\mathrm{D} / \mathrm{T}$ relationship, indicating that protolith, diagenetic effects and tectonic environment influence the observed thickness increase. 
Fault seal considerations of faults in carbonates are challenged by limited input data. On the contrary, conventional geo-modelling software aimed on sandstone reservoirs that calculate across-fault transmissibility, consider large datasets on the distribution of shale along the fault. Key parameters are thickness and composition of the protolith shale layer and displacement on the fault, whereas intrinsic fault complexity is neglected.

Our analysis of extensional faults in carbonates aims at providing a better prediction of fault core characteristics. We analyze the spatial distribution of fault core elements by applying the Fault Facies concept that is developed for 3D fault description and reservoir modelling purposes. The fault envelope is populated with fault facies originating from the host rock, which are linked to field datasets on dimensions, geometry, internal structure, petrophysical properties, and spatial distribution of structural elements.

The analysed dataset is from extensional faults in fine grained carbonates of western Sinai (Egypt), Central Spitsbergen (Arctic Norway), and Central Oman (Adam Foothills) that has a maximum burial of 2-3 kilometres. Studied faults have displacement between one and hundreds of meters. Factors of importance for transmissibility in and across faults include the overall thickness, intrinsic composition and geometry of the fault cores.

The fault cores in the study can be divided into several fault facies and facies association. Based on geometry, cores divide into distributed and localized fault cores, which can be further sub-divided into facies such as shale smear, carbonate fault rocks and cement/secondary calcite layers (Fig. 1). Fault cores in carbonates may widen during faulting by segment growth and linkage by several mechanisms; (1) irregularities such as breached relays and asperities are broken down by progressive faulting and fracturing to eventually form a thicker fault rock layer, (2) precipitation of secondary calcite in the core, and (3) by accumulation of shale smear along the fault core. The total dataset shows a positive correlation between thickness (T) of fault cores and the displacement (D) on faults. The data is scattered over three orders of magnitude, with a $\mathrm{D} / \mathrm{T}$ range of $1: 1$ to $1: 1000$. The $\mathrm{D} / \mathrm{T}$ relationship is not constant, in that $\mathrm{D} / \mathrm{T}$ are generally higher for small faults than for larger faults. Hence, small scaled faults are relatively thicker than large scale faults. When analysing individual fault facies of the core, the $\mathrm{D} / \mathrm{T}$ relationship shows different scaling properties. Viable $\mathrm{D} / \mathrm{T}$ relationships are obtained for core facies such as fault rocks and composite cores (combination of shale smear, carbonate fault rocks and secondary calcite layers), whereas shale smears, secondary calcite layers and gouge membranes are not obeying any trends.

The fault composition reflected by fault facies is varying with displacement. In small scale faults (0-1 m displacement), the major facies is secondary calcite layers and fault gouge, whereas shale dominated fault rocks (shale smear) and carbonate dominated fault rocks (breccias) represent equal, minor components. Shale dominated fault rocks are restricted to shale-rich protoliths, and fault breccias to break-down of lenses formed near fault jogs. For medium scale faults $(1-10 \mathrm{~m})$, fault rocks constitute most of the fault cores, whereas secondary calcite layers decreases in amount due to transformation into breccias. Further, in shale rich carbonates the fault cores consist of composite facies associations. In major faults (10-300 m displacement) the fault rock layers and lenses dominate the fault cores, while composite cores occupy a significant part of the distribution. A common observation in large scale faults is a distinct layering of different fault rocks, shale smearing of major shale layers and massive secondary calcite layers along slip surfaces.

Our analysis of fault core elements with respect to $\mathrm{D} / \mathrm{T}$ shows that fault thickness relates to given facies, which make up distinct parts of the fault core. Fault core heterogeneity in carbonates is ascribed to the distribution of fault facies, such as fault rocks, secondary calcite layers and shale smear. In a broader sense, facies distribution and thickness are controlled by displacement, protolith and tectonic environment. For fault seal considerations, heterogeneous properties and the varied distribution of fault facies in carbonates undermines simple transmissibility considerations. Fault seal should be addressed in models capturing the complexity of fault envelopes, opening for along fault flow and related communication between non-juxtaposed reservoirs. 


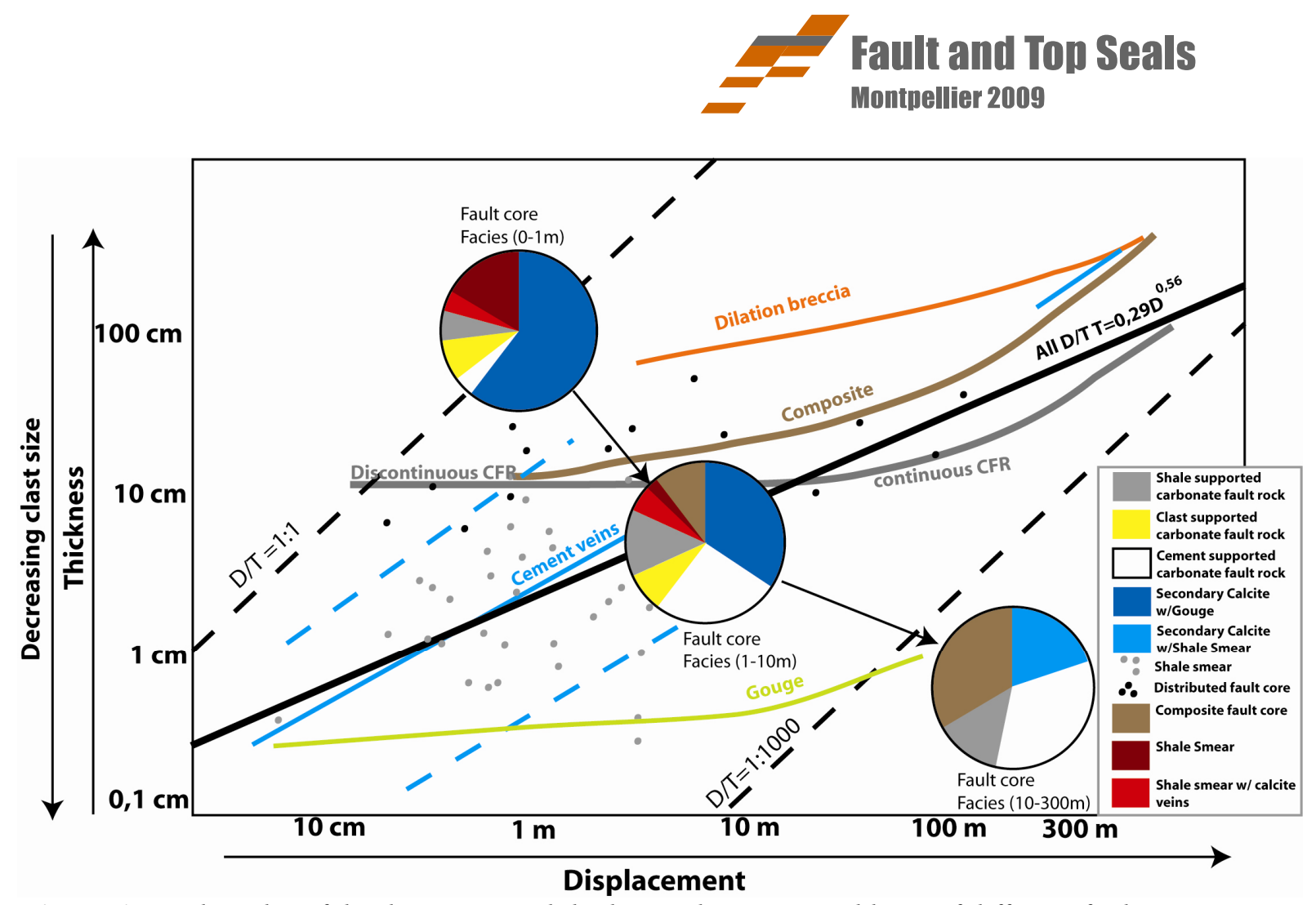

Figure 1 Log-log plot of displacement and thickness showing trend lines of different fault core facies and the best fit power law regression line of the entire dataset (black line). The pie charts display the distributions of facies according to different displacement scales and clast sizes in fault rocks. 